\title{
Transcriptomic Analysis of Avocado Hass (Persea americana Mill) in the Interaction System Fruit-Chitosan-Colletotrichum
}

OPEN ACCESS

Edited by:

Gabor Jakab,

University of Pécs, Hungary

Reviewed by:

Oswaldo Valdes-Lopez, National Autonomous University of

Mexico, Mexico

Raffaella Balestrini,

Consiglio Nazionale Delle Ricerche

(CNR), Italy

*Correspondence:

Luis Herrera-Estrella

Iherrera@langebio.cinvestav.mx

Julio Vega-Arreguín

jvega@enes.unam.mx

Alejandra Chacón-López

mchacon@ittepic.edu.mx;

alei.chacon@gmail.com

Specialty section:

This article was submitted to Plant Microbe Interactions,

a section of the journal

Frontiers in Plant Science

Received: 01 February 2017

Accepted: 22 May 2017

Published: 08 June 2017

Citation:

Xoca-Orozco L-Á, Cuellar-Torres EA, González-Morales S,

Gutiérrez-Martínez P, López-García U, Herrera-Estrella L, Vega-Arreguín $J$

and Chacón-López A (2017)

Transcriptomic Analysis of Avocado

Hass (Persea americana Mill) in the

Interaction System

Fruit-Chitosan-Colletotrichum.

Front. Plant Sci. 8:956.

doi: 10.3389/fp/s.2017.00956

\begin{abstract}
Luis-Ángel Xoca-Orozco ${ }^{1}$, Esther Angélica Cuellar-Torres ${ }^{1}$, Sandra González-Morales ${ }^{2}$, Porfirio Gutiérrez-Martínez ${ }^{1}$, Ulises López-García ${ }^{1}$, Luis Herrera-Estrella ${ }^{2 *}$, Julio Vega-Arreguín ${ }^{3 *}$ and Alejandra Chacón-López ${ }^{1 *}$

${ }^{1}$ Laboratorio Integral de Investigación en Alimentos, Instituto Tecnológico de Tepic, Tepic, Mexico, ${ }^{2}$ Laboratorio Nacional de Genómica Para la Biodiversidad, Center for Research and Advanced Studies of the National Polytechnic Institute (CINVESTAV), Guanajuato, Mexico, ${ }^{3}$ Laboratorio de Ciencias AgroGenómicas, Escuela Nacional de Estudios Superiores, Universidad Nacional Autónoma de México, Guanajuato, Mexico
\end{abstract}

Avocado (Persea americana) is one of the most important crops in Mexico as it is the main producer, consumer, and exporter of avocado fruit in the world. However, successful avocado commercialization is often reduced by large postharvest losses due to Colletotrichum sp., the causal agent of anthracnose. Chitosan is known to have a direct antifungal effect and acts also as an elicitor capable of stimulating a defense response in plants. However, there is little information regarding the genes that are either activated or repressed in fruits treated with chitosan. The aim of this study was to identify by RNA-seq the genes differentially regulated by the action of low molecular weight chitosan in the avocado-chitosan-Colletotrichum interaction system. The samples for RNA-seq were obtained from fruits treated with chitosan, fruits inoculated with Colletotrichum and fruits both treated with chitosan and inoculated with the fungus. Non-treated and non-inoculated fruits were also analyzed. Expression profiles showed that in short times, the fruit-chitosan system presented a greater number of differentially expressed genes, compared to the fruit-pathogen system. Gene Ontology analysis of differentially expressed genes showed a large number of metabolic processes regulated by chitosan, including those preventing the spread of Colletotrichum. It was also found that there is a high correlation between the expression of genes in silico and qPCR of several genes involved in different metabolic pathways.

Keywords: avocado Hass, C. gloeosporioides, RNA-seq, chitosan, elicitor, resistance

\section{INTRODUCTION}

The avocado (Persea americana) cv Hass, is from the economic point of view, one of the most important fruits in Mexico because it is the main producer, exporter and consumer of this fruit in the world. However post-harvest diseases represent a serious problem for exports of avocado fruit. Anthracnose, caused by Colletotrichum sp., is one of the most economically important diseases of the avocado fruit during storage and marketing, with losses close to $20 \%$ of the total avocado production (Freeman et al., 1996; Rodríguez-López et al., 2009). To control this pathogen, chemical fungicides are normally used, even though they have the potential of affecting the environment 
and the health of consumers (Brent and Hollomon, 2007). For this reason it is important to seek biological alternatives to the use of fungicides, such as chitosan, which has no polluting characteristics and acts as an elicitor of plant defense responses. Chitosan, or poly [ $ß$ - (1-4) -2-amino-2-deoxy-D-glucopyranose], is a copolymer of $\mathrm{N}$-acetyl-D-glucosamine units derivative from chitin by a deacetylation treatment in alkaline medium (Islam et al., 2011). The elicitor activity of chitosan is well documented, for instance, it has been reported that upon external application of chitosan the production of chitinases, protease inhibitors and phytoalexins can be induced, triggering a defense response in plants (Terry and Joyce, 2004; Amborabé et al., 2008). However, the mechanism by which chitosan elicits a defense response in plants is not fully elucidated, although some reports indicate that secondary metabolites could have an important role in this response. For example, chitosan application in pear (Pyrus pyrifolia L. cv. Xuehua) resulted in an increase of phenylalanine ammonia lyase (PAL), polyphenol oxidase (PPO) and peroxidase (POD) activities, as well as in the induction of the expression of $\beta$ 1,3-glucanase and chitinase genes, which may also be involved in defense against Alternaria kikuchiana and Physalospora piricola (Meng et al., 2010). Similarly, using a chitosan film in tomato (Lycopersicon esculentum Mill) it was observed an increase in the PPO and POD activities, and in the production of phenolic compounds that correlated with an increase of resistance against Botrytis cinerea and Penicillium expansum (Liu et al., 2007). Moreover, in Arabidopsis seedlings chitosan regulated the expression of defense response genes against Botrytis cinerea and the genes involved in biosynthesis of camalexin (Povero et al., 2011). The activity of enzymes like PAL and tyrosine ammonialyase (TAL) and the expression of genes like those encoding for PPO, POD and Isoflavone Synthase I and II, have been reported to increase in the presence of chitosan in mango fruit (Khan et al., 2003; Berumen-Varela et al., 2015) and soybean (Chen et al., 2009). More recently, RNA-seq analysis has allowed the identification of defense genes induced in orange leaves upon treatment with chitosan, such as different transcription factors and genes involved in some hormone pathways (Coqueiro et al., 2015). In spite of these previous studies, the mechanism by which the chitosan is perceived by the plant and how it induces resistance remains unknown, therefore it is important to design studies that could help shed some light on these processes.

With the aim of having a better understanding of the mechanisms of action of chitosan in the induction of resistance to Colletotrichum sp. in avocado fruit, here we analyzed the global transcriptional profile of avocado fruits treated with chitosan and in the presence or absence of Colletotrichum. We also report on the differentially expressed genes in response to chitosan that could be involved in the resistance induced by this elicitor.

\section{MATERIALS AND METHODS Isolation and Identification of Colletotrichum sp. from Avocado Fruits}

In order to isolate and identify the pathogen causing anthracnose symptoms in avocado, we used fruits that were harvested at physiological maturity stage from an orchard located in Tepic, Mexico. Fungus development was encouraged by placing fruits in chambers at a relative humidity of $90-95 \%$ and $25^{\circ} \mathrm{C}$ for 5 days. Once disease symptoms were developed in the fruit, damaged tissue was washed by immersion in sodium hypochlorite solution (2\%) for $2 \mathrm{~min}$, rinsed with sterile water for $2 \mathrm{~min}$ and placed on filter paper to eliminate moisture. Moisture-free tissue sections were placed on potato dextrose agar (PDA) (DIBCO) and incubated at $25^{\circ} \mathrm{C}$ for $24-72 \mathrm{~h}$. Fungus genus was determined according to the taxonomic keys described by Barnett and Hunter (1998) and by molecular techniques using amplification of ITS1 and ITS4 primers according to White et al. (1990).

\section{Fruit Maturity and Sampling Time}

To establish the sampling times for the RNA-seq analysis, we first evaluated the development of anthracnose symptoms caused by Colletotrichum gloeosporioides in avocado fruits at different states of maturity: physiological, intermediate and consumer maturity. For this, 10 fruits (for each state of maturity) were inoculated with $4 \mu \mathrm{L}$ spore suspension $\left(1 \times 10^{6} \mathrm{~mL}^{-1}\right)$ of C. gloeosporioides previously isolated. Development of the infection was monitored in a stereoscope to follow the fruit invasion by the fungus at $0,1,2,6,9,24,72$, and 96 h postinoculation. For RNA-seq experiments we then selected the maturity state "intermediate" and sampling times at $0,1,6,9$, and $24 \mathrm{~h}$ post-inoculation. In order to study the elicitor effect of chitosan, another group of 10 fruits in a state of "intermediate" maturity were inoculated with $40 \mu \mathrm{L}$ of the spore suspension and treated with a solution of low molecular weight chitosan (LMWC) $1.5 \%(\mathrm{w} / \mathrm{v}$ ) (Sigma Aldrich; viscosity $35 \mathrm{cps}$ in $1 \%$ chitosan solution; $96.1 \%$ deacetylation), the inoculated/treated

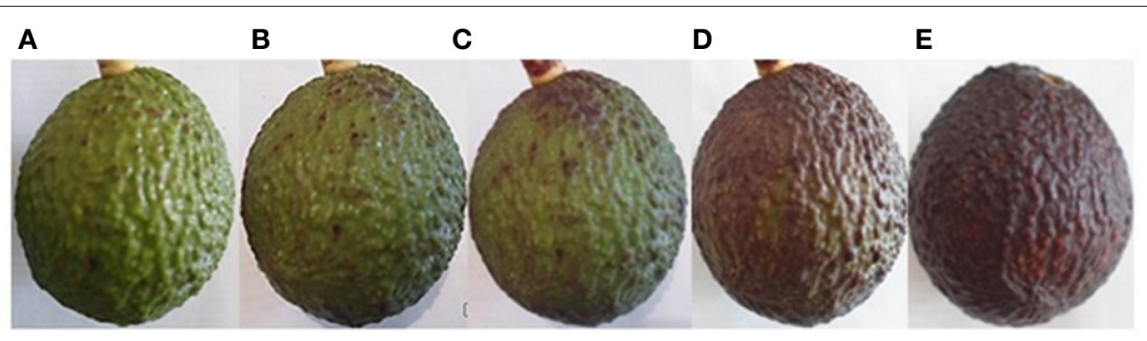

FIGURE 1 | Scale of avocado fruit ripening. (A,B) Post-harvest day, 24\% dry Matter, firmness > 120 Newton. (C,D) Intermediate maturity (between day 5 and 8 post-harvest, $25^{\circ} \mathrm{C}$ ), firmness $60-80$ Newton. (E) Consumption maturity after 10 days post-harvest, $25^{\circ} \mathrm{C}$, firmness $<20$ Newton. 


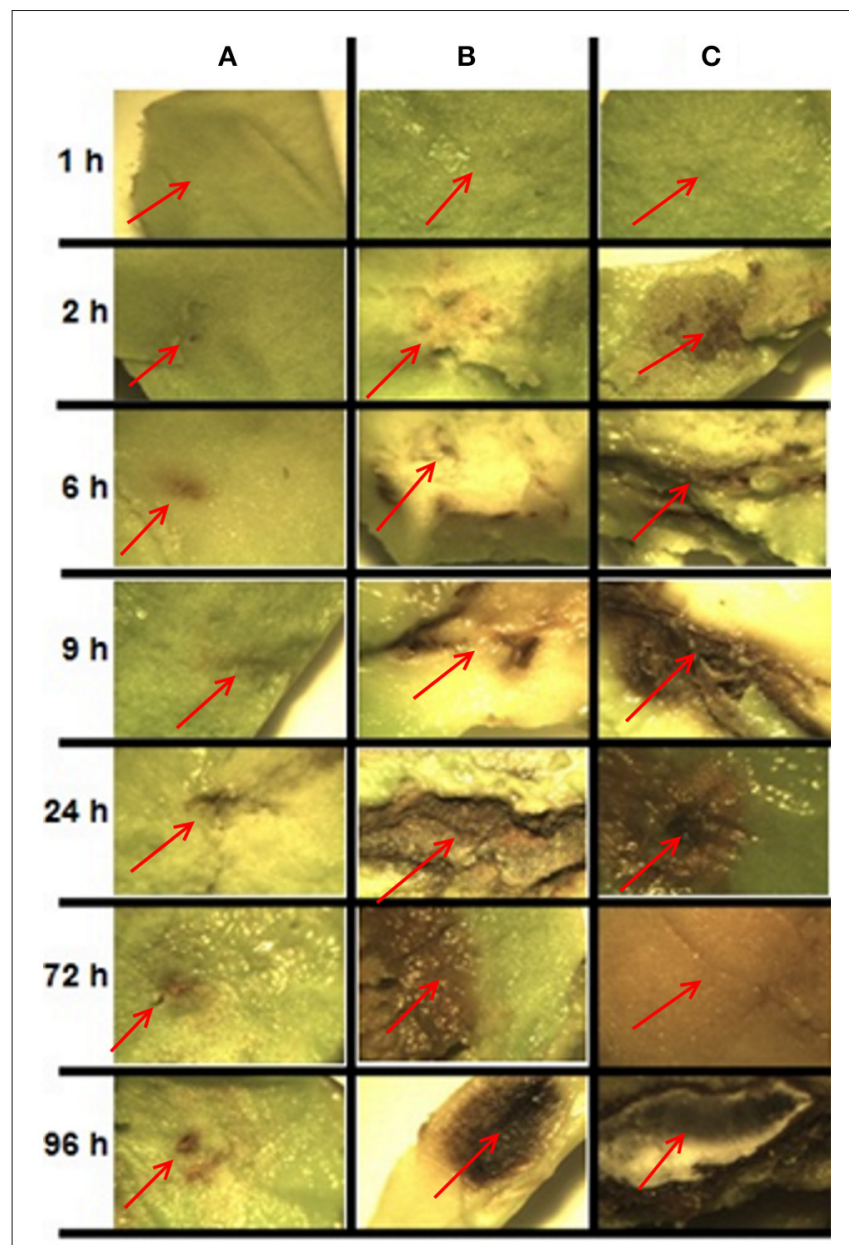

FIGURE 2 | Development of infection caused by inoculation of $C$

gloeosporioides in fruits at different stages of maturity and at different post inoculation times. Each panel shows the pulp of avocado fruit of the area around the inoculation site. (A) Physiological maturity, (B) intermediate maturity, (C) consumption maturity. The red arrow indicates the inoculation site.

fruits were kept at $25^{\circ} \mathrm{C}$ for 7 days to record the disease development.

\section{Chitosan Treatment}

After determining the appropriate sampling conditions for RNAseq, four treatments were performed: untreated control fruits (C), fruits inoculated with C. gloeosporioides (P), fruits treated with LMWC without pathogen $(\mathrm{Q})$ and fruits inoculated with C. gloeosporioides and treated with LMWC (QP). Pathogen inoculation ( $\mathrm{P}$ and $\mathrm{QP}$ treatments) was performed using an insulin syringe as follows: $40 \mu \mathrm{L}$ of a spore suspension $(1 \times$ $10^{6}$ spores $/ \mathrm{mL}$ ) were inoculated by penetrating $3 \mathrm{~mm}$ into the fruit peel, C and Q treatments were inoculated with $40 \mu \mathrm{L}$ of sterile water. After $30 \mathrm{~min}$, fruits were immersed during 1 min into LMWC solution at $1.5 \% \mathrm{w} / \mathrm{v}$, the treatments that did not contain chitosan ( $\mathrm{C}$ and $\mathrm{P}$ ) were immersed in sterile water also for $1 \mathrm{~min}$. Sample collection was performed by cutting sections of $5 \times 5 \mathrm{~cm}$ of peel and pulp of the avocado fruits, which were immediately frozen in liquid nitrogen and

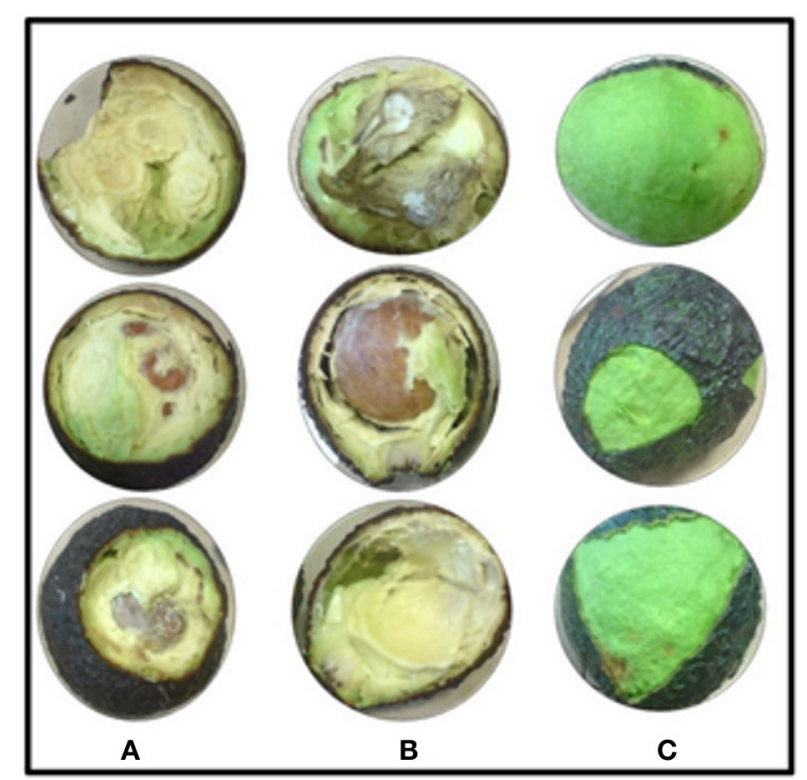

FIGURE 3 | Avocado fruit maturity at the intermediate state, within 7 days of treatment. (A) Control fruits (without chitosan, not-inoculated). (B) Inoculated fruits without chitosan. (C) Inoculated fruits and treated with Chitosan.

Symptoms in $\mathbf{( A , B )}$ belong to anthracnose, (softening pulp and characteristic mycelium development of $C$. gloeosporioides), whereas in (C) fruits treated with chitosan, do not present development of $C$. gloeosporioides.

macerated to a fine powder in a sterile mortar. Samples of three biological replicates of each treatment were stored independently as powder at $-80^{\circ} \mathrm{C}$ for later use. For all these treatments samples were taken at: initial time $(0 \mathrm{~h})$, early response $(1,6$, and $9 \mathrm{~h}$ ) and late response $(24 \mathrm{~h})$. Samples 6 and $9 \mathrm{~h}$ were mixed, because no differences in the development of the disease were observed.

\section{RNA Extraction and Sequencing}

RNA extraction was performed for each of the biological replicates according to the methodology proposed by Djami-Tchatchou and Straker (2012). Then samples from the same treatment were mixed equimolarly. cDNA library preparation and sequencing was carried out at the National Laboratory of Genomics for Biodiversity (LANGEBIO-CINVESTAV-Irapuato, Mexico). Illumina HiSeq 2000 system was used and the sequencing run was $2 \times 100$ (paired-end). Raw data were obtained as FASTQ files, which include reads and their qualities defined based on PHRED, with an average quality $>30$. Raw sequencing data is available at NCBI under accession number SUB2518488.

\section{Bioinformatics Analysis}

\section{Sequence Mapping}

A reference transcriptome of avocado (Persea americana Mill) var drymifolia (TAD) (Ibarra-Laclette et al., 2015) and also a reference transcriptome of avocado fruit (Persea 
TABLE 1 | Comparison of the mapped of sequences ${ }^{a}$ of different treatments using two transcriptomes of Persea americana: avocado drymifolia (TAD) and avocado Hass (TFH).

\begin{tabular}{|c|c|c|c|c|c|c|c|c|}
\hline \multirow[t]{2}{*}{ Condition } & \multirow[t]{2}{*}{ Time (h) } & \multirow{2}{*}{$\begin{array}{l}\text { Total Reads } \\
\text { Paired-end }\end{array}$} & \multicolumn{2}{|c|}{${ }^{b} A C E=1$} & \multicolumn{2}{|c|}{${ }^{c}$ ACE $>1$} & \multicolumn{2}{|c|}{$\%$ Overall alignment } \\
\hline & & & TAD & TFH & TAD & TFH & TAD & TFH \\
\hline & 0 & $20,631,843$ & 21.9 & 60.9 & 67.1 & 21.5 & 92.9 & 89.7 \\
\hline \multirow[t]{3}{*}{ Control fruits } & 1 & $15,265,622$ & 19.5 & 60.7 & 66.8 & 21.3 & 93.4 & 91 \\
\hline & $6 / 9$ & $16,360,548$ & 18.3 & 60.4 & 67.1 & 19.4 & 92.4 & 88.8 \\
\hline & 24 & $21,012,239$ & 17 & 64.6 & 71.1 & 17.5 & 94.1 & 90.4 \\
\hline \multirow[t]{4}{*}{ Inoculated (P) } & 0 & $26,558,994$ & 18.6 & 62.4 & 71 & 19.5 & 94 & 89.1 \\
\hline & 1 & $40,574,501$ & 16.9 & 61.2 & 68 & 17.4 & 92.9 & 88.9 \\
\hline & $6 / 9$ & $18,767,327$ & 17.9 & 61.7 & 70 & 19.7 & 94.4 & 90 \\
\hline & 24 & $21,095,442$ & 17.6 & 63.2 & 71.8 & 19.6 & 94.6 & 90.4 \\
\hline \multirow[t]{4}{*}{ Chitosan treatment (Q) } & 0 & $16,596,262$ & 17.2 & 70.7 & 69.9 & 10.3 & 94.5 & 90.9 \\
\hline & 1 & $17,946,164$ & 18.2 & 58.5 & 64.6 & 17.4 & 91.2 & 86.9 \\
\hline & $6 / 9$ & $15,299,619$ & 20.8 & 60.8 & 68 & 21.3 & 93.2 & 89.2 \\
\hline & 24 & $13,715,619$ & 19.7 & 60.4 & 67.7 & 19.4 & 92.7 & 87.8 \\
\hline \multirow[t]{4}{*}{ Chitosan treatment and inoculated (QP) } & 0 & $15,457,171$ & 17.3 & 61.3 & 68.4 & 17.7 & 92.9 & 88.4 \\
\hline & 1 & $16,702,260$ & 19 & 61.4 & 67.4 & 18.8 & 92.7 & 88.6 \\
\hline & $6 / 9$ & $18,244,858$ & 19.6 & 61.6 & 70.3 & 21.1 & 93.8 & 89 \\
\hline & 24 & $18,901,106$ & 14.1 & 63.7 & 72.8 & 13.5 & 90.4 & 84.4 \\
\hline
\end{tabular}

a Values of $A C E=1, A C E>1$ and overall alignment represent the percentage of alignment using Bowtie2 program, $P<0.05$.

${ }^{b}$ Aligned concordantly exactly 1 time.

${ }^{c}$ Aligned concordantly $>1$ times.

TABLE 2 | Differential expression profile ${ }^{a}$ of different treatments using two reference transcriptomes of Persea americana: var drymifolia (TAD) and avocado Hass (TFH).

\begin{tabular}{|c|c|c|c|c|c|c|c|}
\hline \multirow[t]{2}{*}{ Comparison matrix } & \multirow[t]{2}{*}{ Condition_time } & \multicolumn{2}{|c|}{${ }^{b}$ Down-Regulated } & \multicolumn{2}{|c|}{ Up- regulated } & \multicolumn{2}{|c|}{${ }^{\mathrm{c}}$ TDE } \\
\hline & & TAD & TFH & TAD & TFH & TAD & TFH \\
\hline \multirow[t]{4}{*}{ Inoculated (P) vs. control fruit } & P_O & 27 & 15 & 240 & 154 & 1,888 & 1,422 \\
\hline & $P_{-} 1$ & 296 & 258 & 1,139 & 912 & & \\
\hline & P_6/9 & 20 & 9 & 21 & 19 & & \\
\hline & P_24 & 233 & 141 & 295 & 179 & & \\
\hline \multirow[t]{4}{*}{ Inoculated $(P)$ and chitosan treatment $(Q)$ vs. control fruit } & QP_0 & 172 & 178 & 901 & 755 & 3,031 & 3,112 \\
\hline & QP_1 & 63 & 70 & 314 & 267 & & \\
\hline & QP_6/9 & 16 & 17 & 70 & 53 & & \\
\hline & QP_24 & 187 & 187 & 2,130 & 2,302 & & \\
\hline \multirow[t]{4}{*}{ Chitosan treatment (Q) vs. control fruit } & Q_0 & 129 & 143 & 1,372 & 1,126 & 2,880 & 2,587 \\
\hline & Q_1 & 359 & 355 & 1,838 & 1,689 & & \\
\hline & Q_6/9 & 5 & 8 & 52 & 53 & & \\
\hline & Q_24 & 86 & 66 & 56 & 67 & & \\
\hline
\end{tabular}

a Values represent $\log _{2}$ (Fold Change), p_value $<0.05$

${ }^{b} \log _{2}(F C)<-2$ are Down-Regulated unigenes and $\log _{2}(F C)>+2$ are Up-Regulated unigenes.

${ }^{c} T D E$ : Total differential expression for each comparison. Up and Down regulated unigenes.

americana Mill) cv Hass (TFH) (Kilaru et al., 2015) were used. The Bowtie2 program was used for mapping (Langmead and Salzberg, 2012), this tool also allows us to obtain the read count for any particular gene model. Counting and determination of FPKM (Fragments Per Kilobase of transcript per Million mapped reads) was performed using the program eXpress (Roberts and Pachter, 2013).

\section{Statistical Analysis}

Differentially expressed genes were identified by maximum likelihood analysis $(P<0.05)$ using the $\mathrm{R}$ statistical (Foundation 


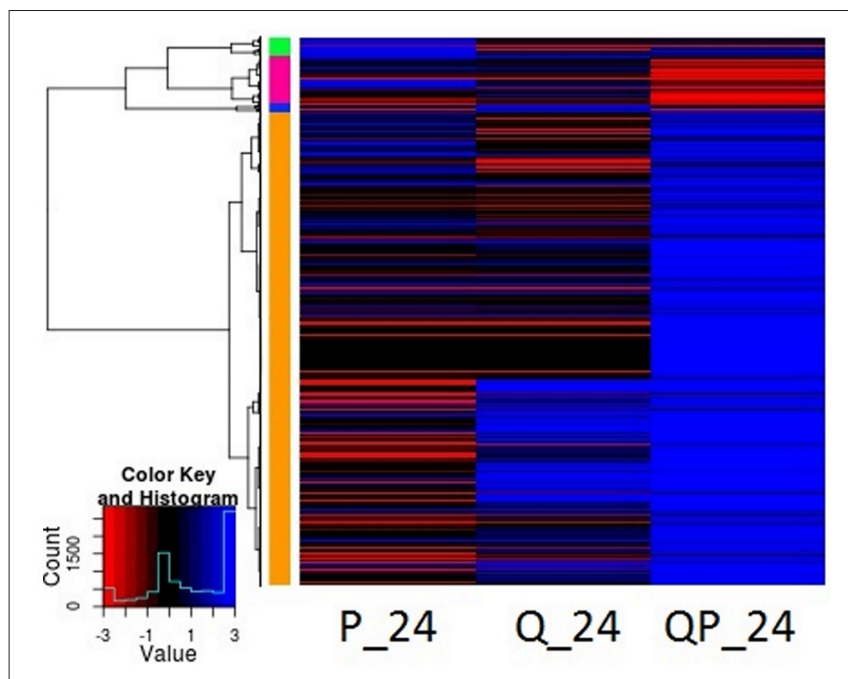

FIGURE 4 | Heatmap representation of differentially expressed genes in $P, Q$, and QP conditions at $24 \mathrm{~h}$ post infection. Results are shown from mapping with avocado Hass transcriptome. Each line represents a differentially expressed gene. Red color represents down-regulated genes, blue color up-regulated and black color no differential expression gene. Most genes of the QP condition were mostly induced. HeatMap with $\mathrm{R}$ statistical program was used.

for Statistical Computing, 2013) with the EdgeR library (McCarthy et al., 2012). The matrix was compared using information from the control samples (fruit not treated with chitosan and not inoculated at their respective sampling times).

\section{Functional Annotation}

To identify enriched GO terms (Process; Up-regulated and Down-regulated genes) Plant MetGenMAP (Ontology Process, multi-test correction FDR, $p$-value < 0.05) (Joung et al., 2009) as well as Classification SuperViewer (Provart and Tong, 2003) were used. For this analysis we used genes showing highest homology to $A$. thaliana genes, eliminating those locus that were repeated. Likewise, the MapMan program (Usadel et al., 2009) was used to identify genes that are specific of metabolic pathways of interest.

\section{Gene Expression Validation}

To validate the bioinformatics analysis on gene expression prediction based on the RNA-seq data, we used real-time RT-PCR for quantification of several avocado transcripts. For this, aliquots were taken from the same RNA that was used for sequencing, cDNAs were synthesized from $2 \mu \mathrm{g}$ of total RNA using the Superscript II (Invitrogen), first strand synthesis procedure was followed by RNase $\mathrm{H}$ digestion (Invitrogen, Carlsbad, CA, USA) according to the manufacturer's instructions. Primers for different genes encoding transcription factors, plant disease resistance proteins, genes involved in ethylene biosynthesis and secondary metabolites, as well as a gene as internal control (Table S1) were used. The primers were designed using the Primer Express 2.0 software (Applied Biosystems, Foster City, CA, USA) with melting temperatures $(\mathrm{Tm})$ of $58-60^{\circ} \mathrm{C}$, primer lengths of 20-24 bp, and amplicon lengths of 61-150 bp. PCR reactions were performed in 48-well plates in a StepOne ${ }^{\mathrm{TM}}$ RealTime PCR System (Applied Biosystems) using SYBR ${ }^{\circledR}$ Green. Three technical replicates were performed for each evaluation. Reactions were done in $25 \mu \mathrm{l}$ containing $200 \mathrm{nM}$ of each primer, $5 \mu \mathrm{l} \mathrm{cDNA}$ (corresponding to $\sim 3 \mathrm{ng}$ ), and $12.5 \mu \mathrm{l} 2 \times$ SYBR Green Master Mix Reagent (Applied Biosystems). PCR parameters were as recommended by the manufacturer: $95^{\circ} \mathrm{C}$ for $10 \mathrm{~min}, 40$ cycles of $95^{\circ} \mathrm{C}$ for $15 \mathrm{~s}$, and $60^{\circ} \mathrm{C}$ for $1 \mathrm{~min}$. Nontemplate controls were included for each primer pair and each PCR reaction was completed in triplicate. Dissociation curves for each amplicon were then analyzed to verify the specificity of each amplification reaction; the dissociation curve was obtained by heating the amplicon from 60 to $95^{\circ} \mathrm{C}$.

\section{RESULTS}

\section{Isolation and Identification of the Pathogen Causing Anthracnose}

Colletotrichum gloeosporioides is the causal agent of anthracnose in avocado fruits, whose characteristic is to remain dormant until the fruit ripens to the maturity consumer stage, when the defense system of the fruit is less active, allowing an easier and more effective infection (Rodríguez-López et al., 2009). Symptoms of anthracnose in avocado fruits were characterized as black sunken lesions with salmon-colored dots in the center and white mycelial growth on the surface. Pathogen identification at species level was performed by isolating the fungus from diseased avocado and grown in culture media. Morphological characterization was performed by evaluating mycelial growth at random, white mycelium, cottony little consistency, grayish colony, short hyphae on the edge of growth and yellowing in the bottom of the petri dish. Microscopic analysis showed that the isolate, according to taxonomic keys, belongs to the genus Colletotrichum (hyaline conidia, form straight, cylindrical and obtuse at the apex, measuring 9-24 um in length and 34.5 um width), while the amplification of ITS1 and ITS4 and subsequent fragment sequencing showed a $98 \%$ homology to $C$. gloeosporioides (File S2).

\section{Determination of Ripeness of the Fruit for RNA-Seq}

To determine the ripeness of the fruit for later transcriptomic analyses, a scale of maturity was established according to the fruit color change from the first postharvest day to maturity consumption stage (Figure 1). During the first 5 days the fruit is in physiological maturity, between 6 and 9 days we considered it as "intermediate maturity," and after day 10 it is in consumption maturity (stored at $25^{\circ} \mathrm{C}$ ).

In order to determine the sampling times for RNA extraction and sequencing, samples were collected from C. gloeosporioides inoculated avocado fruits (without chitosan treatment) at different stages of maturity (physiological, intermediate and consumption) and analyzed for disease symptoms (Figure 2). Inoculated fruits at the physiological maturity stage showed no clear symptoms of pathogen infection, possibly because some antifungal compounds present in the fruit during this 

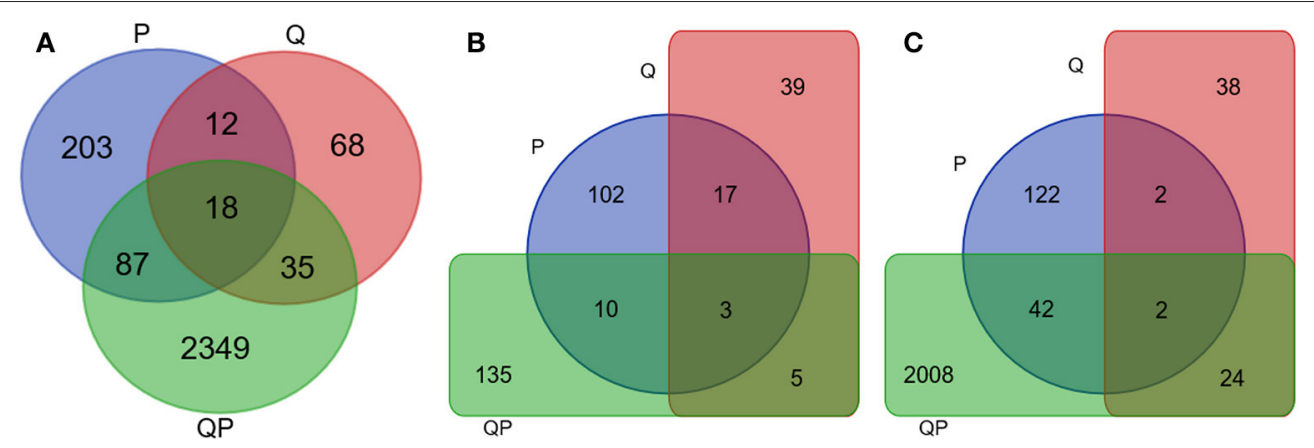

FIGURE 5 | Venn diagram of differentially expressed genes in P (blue), Q (Red), and QP (green) conditions at 24 h. Results from mapping with avocado Hass transcriptome. (A) Up- and down-regulated unigenes. (B) Down-regulated unigenes. (C) Up-regulated unigenes.

stage of maturity prevent fungal infection (Prusky and Lichter, 2007). In fruits at intermediate maturity disease symptoms started to be visible after $9 \mathrm{~h}$ of inoculation and at $96 \mathrm{~h}$ postinoculation a limited area of the fruit showed clear disease symptoms. In contrast, in the fruits at the consumption maturity, disease spreads rapidly, becoming visible as early as $2 \mathrm{~h}$ postinoculation, which became widely spread after $96 \mathrm{~h}$ postinoculation. Since the development of infection in fruits at the intermediate maturity stage was slower and allowed to detect more concise changes during the infection process, we decided to use the intermediate fruit ripening stage to investigate the global transcriptional changes induced by chitosan treatment (Q condition), inoculation by C. gloeosporioides ( $\mathrm{P}$ condition) and both, chitosan treatment and pathogen inoculation in the avocado fruits (QP condition).

\section{Disease Reduction in Avocado Fruits Treated with Chitosan}

Most control fruits developed anthracnose symptoms after 7 days, such as fleshiness and softening pulp (Figure 3A), indicating that C. gloeosporioides was present in its latent state. When fruits were inoculated with $40 \mathrm{~mL}$ of a suspension of $1 \times 10^{6}$ spores $/ \mathrm{mL}$, all of them developed anthracnose and it was observed the growth and invasion of the pathogen covering most of the fruit, showing more drastic symptoms than control fruits (Figure 3B). In contrast, only 10\% of fruits inoculated with C. gloeosporioides and treated with LMWC showed deterioration in quality and the pathogen failed to spread, maintaining a healthy fruit (Figure 3C). These results indicate that LMWC treatment readily increases the avocado fruit resistance against C. gloeosporioides.

\section{RNA-Seq and Mapping to the Reference Transcriptomes}

To obtain and analyze the global transcript profile of the avocado fruit upon treatment/inoculation with chitosan/C. gloeosporioides, RNA samples were obtained from fruits treated with chitosan ( $\mathrm{Q}$ condition), inoculated with the fungus ( $\mathrm{P}$ condition), chitosan-treated and inoculated with the fungus (QP condition) and a control (non-treated and non-inoculated). The
RNA from each condition at different set times, was used for cDNA library preparation and sequenced using the ILLUMINA platform HiSeq 2000. Over 300 million sequences were obtained with an average length of $100 \mathrm{bp}$ in paired-end format. Table 1 shows the number of paired-end reads obtained for each of the treatments. Read alignment to the TAD (Transcriptome Avocado var Drymifolia), resulted in an average of 93\% mapped reads, while alignment to the TFH (Transcriptome Fruit var Hass) resulted in an average of $83 \%$ sequencing reads mapped. However, mapping to the TFH resulted in an increase of reads aligned concordantly exactly 1 time $(\mathrm{ACE}=1$ ) (an average of $62 \%$ ) whereas mapping to the TAD only an average of $18 \%$ of reads $\mathrm{ACE}=1$ were obtained (Table 1 ). Reads aligned concordantly exactly 1 time were used to avoid redundancy in further expression analysis (Langmead and Salzberg, 2012). These mapping differences are possibly due to the different characteristics of the two reference transcriptomes used here, TAD was derived from several organs of the drymifolia avocado plant (including fruit) while TFH was generated from the Hass avocado fruit only (Ibarra-Laclette et al., 2015; Kilaru et al., 2015).

\section{Differential Gene Expression Profiles and Gene Ontology Categorization}

The differential gene expression profiles were obtained to identify those genes in the avocado fruit that were up- or downregulated during treatment with chitosan or/and inoculation with the pathogen. Each of the sequenced libraries showed a similar pattern of the expression profiles using the two reference transcript datasets (TAD and TFH) (Table 2). The results show that, when compared with control fruits (nontreated and non-inoculated), at $1 \mathrm{~h}$ in the condition $\mathrm{P}$ (inoculated vs. control) and Q (treated with LMWC vs. control) the highest amount of unigenes with differential expression is obtained, whereas in QP (inoculated and treated with LMWC vs. control) the highest amount is observed at $24 \mathrm{~h}$. In contrast, the minimum amount of differentially expressed genes was obtained in conditions $P \_0$ and $P \_6 / 9$, whereas in conditions $\mathrm{Q}$ and $\mathrm{QP}$ the minimum amount was at time 6/9. Considering all differentially expressed genes, up-regulated and downregulated, using the two reference transcriptomes, we found 
TABLE 3 | GO Functional Classification of several up- and down- regulated unigenes from treatments at $24 \mathrm{~h}$ that participate in the GO category "Biological process: Response to abiotic or biotic stimulus" (p_value $<0.05$ ).

\begin{tabular}{|c|c|c|c|c|}
\hline Id_unigen ${ }^{a}$ & Locus_At & $\operatorname{Sim}^{\mathbf{b}}$ & Description GOC & $\log _{2} \mathrm{FC}$ \\
\hline \multicolumn{5}{|l|}{ P_24 } \\
\hline UN22478 & AT2G47730 & 54 & Defense response to bacterium & 3.84 \\
\hline UN24431 & AT4G20970 & 59 & Defense response to fungus & 4.28 \\
\hline UN25204 & AT4G37870 & 94 & Defense response to fungus, incompatible interaction & -3.76 \\
\hline UN05540 & AT1G11580 & 64 & Response to bacterium & 4.06 \\
\hline UN09181 & AT3G45140 & 80 & Response to bacterium & 4.27 \\
\hline UN15753 & AT3G16770 & 69 & Response to other organism & -3.95 \\
\hline UN10274 & AT1G20030 & 81 & Response to other organism & 3.53 \\
\hline UN33841 & AT4G36000 & 71 & Response to other organism & 3.84 \\
\hline UN18390 & AT3G28480 & 86 & Systemic acquired resistance & -4.07 \\
\hline UN08200 & AT3G24503 & 78 & Systemic acquired resistance & -2.70 \\
\hline UN24647 & AT1G43800 & 85 & Systemic acquired resistance, salicylic acid mediated signaling pathway & -4.98 \\
\hline UN26087 & AT2G38290 & 59 & Systemic acquired resistance, salicylic acid mediated signaling pathway & -4.37 \\
\hline \multicolumn{5}{|l|}{ Q_24 } \\
\hline UN25204 & AT4G37870 & 94 & Defense response to fungus, incompatible interaction & -2.82 \\
\hline UN09181 & AT3G45140 & 80 & Response to bacterium & 4.50 \\
\hline UN26952 & AT3G02260 & 77 & Response to fungus & 4.92 \\
\hline UN02048 & AT5G42020 & 47 & Response to heat & 2.87 \\
\hline UN33302 & AT3G06490 & 59 & Response to salt stress & -5.04 \\
\hline UN10235 & AT5G13930 & 77 & Response to UV & -3.74 \\
\hline UN17145 & AT3G02550 & 64 & Systemic acquired resistance, salicylic acid mediated signaling pathway & 3.09 \\
\hline UN41590 & AT1G15520 & 79 & Systemic acquired resistance, salicylic acid mediated signaling pathway & 7.48 \\
\hline \multicolumn{5}{|l|}{ Qp_24 } \\
\hline UN22478 & AT2G47730 & 54 & Defense response to bacterium & 4.51 \\
\hline UN41690 & AT1G28480 & 54 & Defense response to bacterium & 4.75 \\
\hline UN61218 & AT2G35930 & 60 & Defense response to fungus & -5.30 \\
\hline UN22722 & AT2G15890 & 48 & Defense response to fungus & 7.03 \\
\hline UN00578 & ATCG00480 & 82 & Defense response to fungus, incompatible interaction & 3.59 \\
\hline UN09181 & AT3G45140 & 80 & Response to bacterium & 4.64 \\
\hline UN49784 & AT3G62550 & 69 & Response to molecule of fungal origin & 5.12 \\
\hline UN02593 & AT1G33440 & 79 & Response to nematode & -3.22 \\
\hline UN15753 & AT3G16770 & 69 & Response to other organism & 3.27 \\
\hline UN39665 & AT5G17760 & 68 & Systemic acquired resistance & -2.46 \\
\hline UN26087 & AT2G38290 & 59 & Systemic acquired resistance, salicylic acid mediated signaling pathway & -3.17 \\
\hline UN24647 & AT1G43800 & 85 & Systemic acquired resistance, salicylic acid mediated signaling pathway & 2.55 \\
\hline UN27548 & AT3G03000 & 84 & Systemic acquired resistance, salicylic acid mediated signaling pathway & 3.06 \\
\hline UN06422 & AT4G13510 & 66 & Systemic acquired resistance, salicylic acid mediated signaling pathway & 3.46 \\
\hline UN20428 & AT4G09650 & 53 & Systemic acquired resistance, salicylic acid mediated signaling pathway & 3.56 \\
\hline UN67382 & AT1G74360 & 73 & Systemic acquired resistance, salicylic acid mediated signaling pathway & 3.62 \\
\hline UN17145 & AT3G02550 & 64 & Systemic acquired resistance, salicylic acid mediated signaling pathway & 5.30 \\
\hline
\end{tabular}

${ }^{a}$ Contig: transcriptome avocado var drymifolia.

b\% Similarity between avocado transcripts (TAD) and A.thaliana (Blast of TAD vs. A.thaliana genome).

${ }^{c}$ Description SuperViewer GO: (http://bar.utoronto.ca/ntools/cgi-bin/ntools_classification_superviewer.cgi).

that at the QP condition a higher differential expression was obtained compared to the control fruit, while in condition $\mathrm{P}$ a smaller amount of differentially expressed unigenes was obtained.

Gene expression analysis at different sampling times shows that at $24 \mathrm{~h}$ most genes of the QP condition were induced $(\mathrm{FC}>+2)$ (Figure 4), whereas in the $\mathrm{P}$ condition were mostly repressed and in the $\mathrm{Q}$ condition the number of genes induced and repressed is similar. More than 2400 genes were differentially expressed in the QP_24 condition, from this set of genes 2000 were induced (Figure 5). Interestingly, the highest number of differential gene expressed was observed in $\mathrm{Q}$ condition at initial times ( 0 and $1 \mathrm{~h}$ ), in contrast we observed that in the same $\mathrm{Q}$ condition there was a minor number of differential 
TABLE 4 | Top 10 enriched GO terms of QP_24. Terms from GO (p-value < 0.05) Up-regulated (530 unigenes) and Down-Regulated (79 unigenes).

\begin{tabular}{|c|c|c|c|c|c|}
\hline \multicolumn{3}{|c|}{ Up-regulated } & \multicolumn{3}{|c|}{ Down-Regulated } \\
\hline Gene ontology term & $\begin{array}{l}\text { Number of } \\
\text { unigenes }\end{array}$ & $\begin{array}{c}\text { Cluster } \\
\text { frequency (\%) }\end{array}$ & Gene Ontology term & $\begin{array}{c}\text { Number of } \\
\text { unigenes }\end{array}$ & $\begin{array}{c}\text { Cluster } \\
\text { frequency }(\%)\end{array}$ \\
\hline Response to stimulus & 91 & 17.20 & Response to stimulus & 15 & 19.00 \\
\hline Response to stress & 61 & 11.50 & Transport & 13 & 16.50 \\
\hline Response to chemical stimulus & 45 & 8.50 & Establishment of localization & 13 & 16.50 \\
\hline Response to abiotic stimulus & 31 & 5.80 & Localization & 13 & 16.50 \\
\hline Response to temperature stimulus & 19 & 3.60 & Response to chemical stimulus & 10 & 12.70 \\
\hline Response to other organism & 17 & 3.20 & Response to endogenous stimulus & 9 & 11.40 \\
\hline Response to heat & 10 & 1.90 & Post-translational protein modification & 9 & 11.40 \\
\hline Response to jasmonic acid stimulus & 10 & 1.90 & Response to hormone stimulus & 8 & 10.10 \\
\hline Response to wounding & 9 & 1.70 & Anatomical structure development & 8 & 10.10 \\
\hline Response to carbohydrate stimulus & 8 & 1.50 & Protein amino acid phosphorylation & 8 & 10.10 \\
\hline
\end{tabular}

expressed genes at long time $(24 \mathrm{~h})$ in comparison with $\mathrm{P}$ and QP conditions. This suggests that the fruit induced its defense system by regulating several genes in short times just after treatment with chitosan.

To identify and assign enriched Gene Ontology (GO) terms to our dataset (Plant MetGenMap, Ontology Process, multi-test correction FDR, p_value $<0.05$ ), all of the differentially upand down-regulated unigenes showing sequence homology to A. thaliana (DNA sequences defined in terms by at least $60 \%$ similarity) were functionally categorized in biological process (BP), cellular component (CC), and molecular function (MF) (Table S3). The gene expression profile from the different conditions, that were analyzed by GO categorization showed important differences. In the P_24 condition some downregulated unigenes were associated with "Systemic acquired resistance (SAR)" and "incompatible interaction with fungus," suggesting that a decrease in the expression of these genes could be the cause of the observed disease development in the fruit. Other unigenes that are up-regulated in the same condition (P) are associated with "Defense response to fungus," but such defense is not effective since the fruit is susceptible in this condition. In contrast, when only chitosan is present (condition Q_24) some of the unigenes that are categorized in biotic stimulus, specifically those involved in SAR response, are up-regulated. The QP_24 condition shows a possible combined response between the processes occurring in both $\mathrm{Q}$ and $\mathrm{P}$ separately, for example, the unigenes UN26087 $\left(\log _{2} \mathrm{FC}=\right.$ -4.37 and $\log _{2} \mathrm{FC}=-3.17, \mathrm{P}$ and $\mathrm{QP}$ conditions, respectively) and UN17145 $\left(\log _{2} \mathrm{FC}=3.09\right.$ and $\log _{2} \mathrm{FC}=5.30, \mathrm{Q}$ and QP conditions, respectively), are both associated with SAR. Interestingly, in the QP condition a considerable increase of the expression was observed in the genes that are classified in this category (Table 3). GO analysis of the QP condition at $24 \mathrm{~h}$ showed processes as response to stimulus, response to stress, response to chemical stimulus and response to abiotic stimulus as the main processes that are affected due to treatment with chitosan and pathogen inoculation (Table 4, and Table S4).

\section{Metabolic Pathways Related to Biotic Stress}

In order to analyze changes in metabolic pathways related to biotic stress in the fruit for each of the treatments, we used the MapMan software (Usadel et al., 2009) based on the homology to $A$. thaliana genes of known function. Several subsets of genes encoding receptor-like kinases, signaling proteins, transcriptional factors, oxidative stress response elements, secondary metabolism factors, phytohormone-responsive genes and defense-related genes were identified. Notably, a greater number of genes were differentially expressed in the QP condition in all of the identified metabolic pathways. As described before, $24 \mathrm{~h}$ after inoculation fruits without chitosan showed characteristic symptoms of infection caused by $C$. gloeosporioides (Figure 2), whereas in chitosan treated fruits infection was not visible and a large number of genes related response to different metabolic processes were induced, mainly genes related to biotic stress responses (Figure 6).

An increase in the expression of unigenes actively involved in metabolic pathways related to biotic stress is observed from early times in fruits treated with LMW chitosan (Q_0) (Table 5). GO classification shows the relationship of some induced unigenes related to SAR and those involved in the salicylic acid and jasmonic acid signaling pathways. Also, a slight induction of genes involved in response to both biotic and abiotic stress is observed, suggesting that a priming state could be acting where the fruit is conditioned for the super-activation of defenses activated by pathogen inoculation.

\section{Gene Expression Validation by qRT-PCR}

To validate and confirm the gene expression results obtained by bioinformatics analysis of our RNA-seq data, we performed real time quantitative RT-PCR of several avocado unigenes that showed different expression patterns (Table 6). For this, we considered unigenes that mapped to both reference transcriptomes and that corresponded to various metabolic pathways such as ethylene, secondary metabolites, transcription factors and pathogenesis related. The results show a trend of 


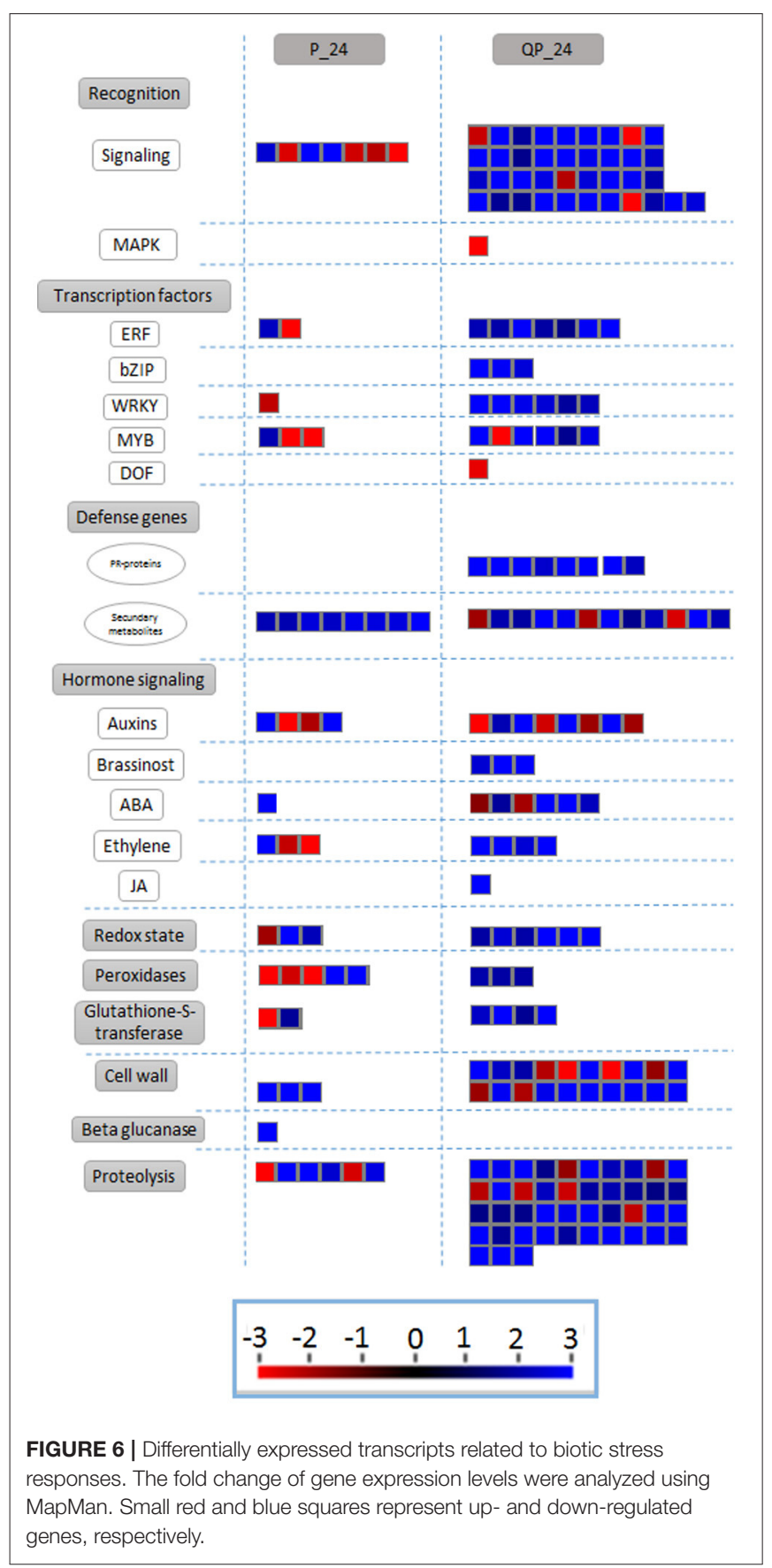

expression as well as a high correlation between the expression results by RNA-seq and qRT-PCR.

\section{DISCUSSION}

\section{RNA Sequencing and Differential Expression Profile}

The use of two reference transcriptomes (TDH and TFH) allowed us to have a greater coverage in the analysis of our sequencing data. The comparative analysis of our data with both reference transcriptomes resulted in different percentage of mapped sequences (Table 1). On average 50\% less of differentially expressed unigenes (induced and repressed) were obtained in the $\mathrm{P}$ condition when compared with those obtained in $\mathrm{Q}$ and QP conditions. On the other hand, the little difference of genes differentially expressed in the $\mathrm{P}$ condition in comparison with the control, could be explained by the fact that the control fruits are frequently naturally infected with the phytopathogen C. gloeosporioides, which is commonly found in the host from early stages of fruit development (Beno-Moualem and Prusky, 2000; Mendgen and Hahn, 2002). Thus, the development of the infection can be observed as the fruit ripens. However, in our experimental setting, we observed that at $1 \mathrm{~h}$ post inoculation, the fruit is highly resistant probably due to the presence of antifungal compounds (Table 2) (Yakoby et al., 2002; Wharton and Diéguez-Uribeondo, 2004; Prusky and Lichter, 2007). By contrast, in the presence of chitosan and the pathogen (QP), there is a strong defense response even at $24 \mathrm{~h}$ post-inoculation (Table 2). We hypothesize that the observed differences between the expression profile in $\mathrm{QP}$ condition in comparison with $\mathrm{Q}$ condition, are possibly due to potentiation of cellular signaling processes, as a consequence of the increased stress in the fruit induced by the chitosan-pathogen-fruit interaction.

The major GO categories for the $\mathrm{P}$ condition were the "response to stress to abiotic or biotic stimulus" and "metabolic processes," whereas in the Q condition there were "cellular processes" and "response to stress to abiotic or biotic stimulus." Interestingly, when the fruit was inoculated with the pathogen and treated with chitosan (QP), a significant increase of differentially expressed genes that were located in several GO categories was observed, for example, "cellular processes," "metabolic processes," "response to stress abiotic or biotic stimulus," "biological processes," "transport," "cell organization and biogenesis" and "signal transduction," this indicate that the chitosan could be able to activate different metabolic pathways involved in the defense of the fruit.

In order to have specific annotation data from the profile expression obtained here, we used the information from $A$. thaliana based on sequence homology. Several avocado unigenes that were involved in SAR and that were induced in the $\mathrm{P}, \mathrm{Q}$, and $\mathrm{QP}$ conditions, have homologs in A. thaliana genes involved in the response to different pathogens. For example, AT3G02550 (leucine-rich repeat receptor-like kinase NILR1) and AT1G74360 (nematode-induced LRR-RLK 1) are required for induction of innate immunity to parasitic nematode (Mendy et al., 2017); AT5G17760 (P-loop containing nucleoside triphosphate hydrolases superfamily) is related to plant response during geminivirus infection (Ascencio-Ibáñez et al., 2008); AT1G15520 (ABCG40 atp-binding cassette g40) is related to Phytophthora resistance (Wang et al., 2015); and AT3G02260 (Calossin-like protein required for polar auxin transport) is involved in immune response to $H$. arabidopsidis (Meteignier et al., 2017) (Table 3). This suggests that the chitosan and/or phytopathogen perception could converge in some signal points activating common metabolic pathways in the fruit. Although different defense responses may be activated depending on the tissue or organ attacked by a pathogen, some common pathways 
TABLE 5 | GO functional classification of unigenes related to "response to biotic stimulus" in fruits treated with chitosan at initial time (Q_0).

\begin{tabular}{|c|c|c|c|c|}
\hline Avocado unigene ${ }^{\mathrm{a} C o n t i g}$ ID & ${ }^{\text {b} A T ~ L o c u s ~ I D ~}$ & ${ }^{c} \log _{2}(F C)$ & ${ }^{\mathrm{d}}$ Gene Ontology & dDescription \\
\hline \multicolumn{5}{|l|}{ Q_0 } \\
\hline PA10010937 & At1g73500 & 1.91 & GO:0009651 & Response to salt stress \\
\hline PA10001010 & At5g17310 & 2.0 & GO:0009651 & Response to salt stress \\
\hline PA10000034 & At3g15353 & 2.0 & GO:0009651 & Response to salt stress \\
\hline UN28089 & At3g04720 & 1.78 & GO:0009627 & Systemic acquired resistance \\
\hline PA10034792 & At2g23810 & 1.87 & GO:0009612 & Response to mechanical stimulus \\
\hline PA10005805 & At5g42050 & 2.08 & GO:0009409 & Response to cold \\
\hline PA10022314 & At3g04120 & 1.63 & GO:0006972 & Hyperosmotic response \\
\hline PA10003223 & At2g22240 & 1.67 & GO:0042742 & Defense response to bacterium \\
\hline PA10024501 & At1g32640 & 2.07 & GO:2000068 & Regulation of defense response to insect \\
\hline \multicolumn{5}{|l|}{ Q_1 } \\
\hline PA10007344 & At5g43060 & 1.95 & GO:0009651 & Response to salt stress \\
\hline PA10010937 & At1g73500 & 1.98 & GO:0009651 & Response to salt stress \\
\hline PA10001010 & At5g17310 & 2.05 & GO:0009651 & Response to salt stress \\
\hline PA10012376 & At5g20250 & 1.77 & GO:0009416 & Response to light stimulus \\
\hline PA10008863 & At2g26710 & 1.97 & GO:0009416 & Response to light stimulus \\
\hline PA10009014 & At1g68050 & 1.93 & GO:0009637 & Response to blue light \\
\hline UN27548 & At3g03000 & 1.86 & GO:0009862 & Systemic acquired resistance, salicylic acid mediated signaling pathway \\
\hline PA10001012 & At3g12490 & 1.72 & GO:0009414 & Response to water deprivation \\
\hline UN11494 & At3g46620 & 2.10 & GO:0009414 & Response to water deprivation \\
\hline PA10007478 & At5g59550 & 2.02 & GO:0009414 & Response to water deprivation \\
\hline PA10022147 & At4g24240 & 1.95 & GO:0009408 & Response to heat \\
\hline PA10001322 & At3g48990 & 1.61 & GO:0050832 & Defense response to fungus \\
\hline UN20644 & At2g35980 & 1.94 & GO:0050832 & Defense response to fungus \\
\hline PA10020372 & At3g12500 & 2.07 & GO:0050832 & Defense response to fungus \\
\hline PA10005138 & At3g05880 & 2.07 & GO:0009266 & Response to temperature stimulus \\
\hline PA10006492 & At2g20990 & 1.80 & GO:0009409 & Response to cold \\
\hline PA10000793 & At1g47128 & 1.56 & GO:0006972 & Hyperosmotic response \\
\hline PA10015059 & At2g22240 & 1.78 & GO:0042742 & Defense response to bacterium \\
\hline UN01018 & At1g55020 & 2.01 & GO:0009816 & Defense response to bacterium, incompatible interaction \\
\hline PA10002905 & At3g05550 & 1.67 & GO:0001666 & Response to hypoxia \\
\hline PA10008712 & At1g17290 & 1.82 & GO:0001666 & Response to hypoxia \\
\hline
\end{tabular}

${ }^{a}$ Contig TAD: UNXXXX; Contig TFH: PA1XXXXXX.

${ }^{b}$ Locus ID A. thaliana gene homology with TAD and TFH unigenes.

${ }^{c} \log _{2}$ (FC), P_value < 0.05 .

${ }^{d}$ Classification SuperViewer Tool w/Bootstrap of locus A. thaliana.

could be present and similarly efficient to stop an infection, however, more studies are needed to shed light on the defense mechanisms induced by elicitors like chitosan in fruits.

The analysis to identify enriched GO terms (Table 4) showed the enrichment of various metabolic processes that could contribute to the resistance of the fruit against C. gloeosporioides. It has been reported that plants treated with chitosan present mostly biochemical and molecular changes that include: chromatin alterations (Hartney et al., 2007; Hadwiger, 2008), increases in cytosolic Ca2+ (Zuppini et al., 2004), activation of MAP-kinases (Yin et al., 2009), oxidative burst (Paulert et al., 2010), callose deposition (Kohle et al., 1985), increase in pathogenesis-related (PR) gene mRNA, PR protein synthesis (Berumen-Varela et al., 2015), phytoalexin accumulation, hypersensitive response (HR) (Hadwiger, 2013), and in some systems, synthesis of jasmonic acid (JA) and abscisic acid (ABA) and accumulation of hydrogen peroxide (Lin et al., 2005; Iriti and Faoro, 2009). Recently, the use of nextgeneration sequencing has allowed different studies that identify global changes in cellular processes that are affected by both biotic and abiotic stress. For example, Coqueiro et al. (2015) identified by RNA-seq different processes that were affected by chitosan treatments in citrus leaves. Here we performed RNASeq analysis in avocado fruit treated/inoculated with chitosan/C. gloeosporioides to identify different metabolic pathways and processes involved in the induced resistance in the fruit.

\section{Activation of the Defense-Priming State}

It has been reported that activation of the defense-priming state is accompanied by processes such as systemic acquired resistance (Jung et al., 2009) and induced systemic resistance (Pieterse et al., 2014), and also by wound-induced resistance (Chassot 
TABLE 6 | Analysis of gene expression and validation by qRT-PCR of several unigenes mapped to Hass transcriptome (TFH) and drymifolia transcriptome (TAD) $(P<0.05)$.

\begin{tabular}{|c|c|c|c|c|}
\hline Contig ID & Name & Sample & ${ }^{b}$ RNA-seq & ${ }^{c}$ qRT-PCR \\
\hline \multirow[t]{3}{*}{ PA10053717 } & WRKY22 & $P_{-} 1$ & 4.79 & 2.9 \\
\hline & & QP_24 & 4.63 & 6.9 \\
\hline & & Q_1 & 5.54 & 4.45 \\
\hline \multirow[t]{4}{*}{ PA10048435 } & Avfae1 & $P_{-} 1$ & 8 & 2.36 \\
\hline & & P_24 & -4.14 & -2.2 \\
\hline & & Q_1 & 7.16 & 3.89 \\
\hline & & QP_1 & 8.41 & 6.84 \\
\hline \multirow[t]{2}{*}{ PA10000364 } & Avfad12-3 & $P_{-} 1$ & 1.96 & 1.62 \\
\hline & & Q_0 & 1.64 & 0.89 \\
\hline PA10002664 & $\mathrm{CHS}$ & Q_1 & -2.14 & -1.03 \\
\hline PA10079021 & NB-arc & $P_{-} 1$ & 3.12 & 3.59 \\
\hline \multirow[t]{3}{*}{ UN37342 } & WRKY22 & $P_{-} 1$ & 4.91 & 2.9 \\
\hline & & Q_1 & 5.75 & 4.45 \\
\hline & & QP_24 & 4.71 & 6.9 \\
\hline \multirow[t]{4}{*}{ UN69179 } & Avfae1 & $P_{-} 1$ & 11.43 & 2.36 \\
\hline & & P_24 & -3.87 & -2.2 \\
\hline & & Q_1 & 10.98 & 3.89 \\
\hline & & QP_1 & 11.87 & 6.84 \\
\hline \multirow[t]{2}{*}{ UN02803 } & Avfad12-3 & $P_{-} 1$ & 2.52 & 1.62 \\
\hline & & Q_0 & 1.61 & 0.89 \\
\hline \multirow[t]{2}{*}{ UN29560 } & ERF & $P_{-} 1$ & 1.91 & 5.26 \\
\hline & & Q_0 & 2.63 & 4.25 \\
\hline UN30532 & 4-CL & Q_0 & 3.16 & 4.99 \\
\hline \multirow[t]{2}{*}{ UN59130 } & NB-arc & $P_{-} 1$ & 4.07 & 3.59 \\
\hline & & Q_1 & 4.23 & 1.16 \\
\hline UN27536 & Avox & QP_24 & 10.31 & 2.58 \\
\hline UN42782 & $\mathrm{CHS}$ & Q_1 & -2.58 & -1.03 \\
\hline UN28880 & FLS & Q_1 & -2.61 & -4.18 \\
\hline
\end{tabular}

${ }^{a}$ Contig TAD: UNXXXX; Contig TFH: PA1XXXXXX.

${ }^{b}$ Log2 (Fold Change).

${ }^{c} \log 2(R Q)$.

et al., 2008). Activation of these processes in short times possibly induces the "state of priming" related to sensitization of a cell or organism for enhanced defense; this condition causes faster and more robust activation of defense responses upon challenge with a pathogen (Conrath et al., 2015). Our results suggest that chitosan could induce a state of priming in short times after application, which promotes effective fruit resistance against C. gloeosporioides (Table 5).
On the other hand, several studies (Wang et al., 2010; Rodríguez-Carpena et al., 2011; Widsten et al., 2014) indicate that there are compounds in the epicarp of avocado fruits, mainly phenolic compounds such as catechins, epicatechin, proanthocyanidins, and quercetin, which have antibacterial and antifungal activity, and a high antioxidant capacity. It has also been identified the diene AFD (1-acetoxy-2-hidroxiy-4-oxoheneicosa 12, 16 diene) (Ardi et al., 1998) with high antifungal capacity. Our analysis showed that treatment of fruits with chitosan downregulates some genes involved in biosynthesis of phenylpropanoids (CHS and FLS) (Table 6) whereas the gene encoding to 4-Coumarate coenzyme A ligase (4CL) is up-regulated. Likewise, we found transcription factors such as WRKY22 (Povero et al., 2011) and ERF (Oñate-Sánchez and Singh, 2002; Vallejo-Reyna et al., 2015) that were induced in different treatments with chitosan compared to control treatments in avocado fruits. According with our results, the genes involved in the biosynthesis of diene AFD (Avfad1 and Avfae12-3) are up-regulated in the fruits treated with chitosan (Table 6), suggesting a direct association between the diene AFD synthesis and chitosan.

The results presented in this study shows that chitosan acts as a molecule able to induce multiple metabolic responses in avocado fruit that collectively implements a defense system capable of counteract the infection by C. gloeosporioides. However, further studies are needed to experimentally determine the role and function of up- and down-regulated genes in fruits treated with chitosan and to dissect their participation in the resistance to pathogens as C. gloesporioides in avocado.

\section{AUTHOR CONTRIBUTIONS}

AC-L provided the idea of the work. AC-L and LX designed the experiments. PG and UL contributed with the in vivo assays in fruit. EC performed the identification of the phytopathogen. LX, SG, and JV performed the bioinformatics analysis. LH contributed in the sequencing and generation of libraries. LX and JV performed qRT-PCR assays. LX, AC-L, JV, and LH participated in the interpretation of results and critically reviewed the manuscript. LX wrote the paper. All authors read and approved the final manuscript.

\section{ACKNOWLEDGMENTS}

Authors express their gratitude to the Mexican National Council for Science and Technology (CONACYT) for financing this work through the Basic Science Research Project \#252423. Partial funding was from DGAPA-UNAM: IA203313-IN214917, and CONCYTEG.

\section{SUPPLEMENTARY MATERIAL}

The Supplementary Material for this article can be found online at: http://journal.frontiersin.org/article/10.3389/fpls.2017. 00956/full\#supplementary-material 


\section{REFERENCES}

Amborabé, B. E., Bonmort, J., Fleurat-Lessard, P., and Roblin, G. (2008). Early events induced by chitosan on plant cells. J. Exp. Bot. 59, 2317-2324. doi: $10.1093 /$ jxb/ern096

Ardi, R., Kobiler, I., Jacoby, B., Keen, N. T., and Prusky, D. (1998). Involvement of epicatechin biosynthesis in the activation of the mechanism of resistance of avocado fruits to Colletotrichum gloeosporioides. Physiol. Mol. Plant Pathol. 53, 269-285. doi: 10.1006/pmpp.1998.0181

Ascencio-Ibáñez, J. T., Sozzani, R., Lee, T.-J., Chu, T.-M., Wolfinger, R. D., Cella, R., et al. (2008). Global analysis of Arabidopsis gene expression uncovers a complex array of changes impacting pathogen response and cell cycle during geminivirus infection. Plant Physiol. 148, 436-454. doi: 10.1104/pp.108.121038

Barnett, H. L., and Hunter, B. B. (1998). Illustrated genera of imperfect fungi. APS Press 38:480.

Beno-Moualem, D., and Prusky, D. (2000). Early events during quiescent infection development by Colletotrichum gloeosporioides in unripe avocado fruits. Phytopathology 90, 553-559. doi: 10.1094/PHYTO.2000.90.5.553

Berumen-Varela, G., Coronado-Partida, D., Ochoa-Jiménez, V., Chacón-López, A., and Gutiérrez-Martínez, P. (2015). Effect of chitosan on the induction of disease resistance against Colletotrichum sp. in mango (Mangifera indica L) cv. Tommy Atkins 66, 16-21. Available online at: http://www.redalyc.org:9081/ articulo.oa?id=67446014003

Brent, K. J., and Hollomon, D. W. (2007). Fungicidce Resistance in Plant Management: How Can It be Managed? Brussels: Fungicide Resistance Action Committee 2007.

Chassot, C., Buchala, A., Schoonbeek, H. J., Métraux, J. P., and Lamotte, O. (2008). Wounding of Arabidopsis leaves causes a powerful but transient protection against Botrytis infection. Plant J. 55, 555-567. doi: 10.1111/j.1365-313X.2008.03540.x

Chen, H., Seguin, P., Archambault, A., Constan, L., and Jabaji, S. (2009). Gene expression and isoflavone concentrations in soybean sprouts treated with chitosan. Crop Sci. 49, 224-236. doi: 10.2135/cropsci2007.09.0536

Conrath, U., Beckers, G. J. M., Langenbach, C. J. G., and Jaskiewicz, M. R. (2015). Priming for enhanced defense. Annu. Rev. Phytopathol. 53, 97-119. doi: 10.1146/annurev-phyto-080614-120132

Coqueiro, D. S. O., de Souza, A. A., Takita, M. A., Rodrigues, C. M., Kishi, L. T., and Machado, M. A. (2015). Transcriptional profile of sweet orange in response to chitosan and salicylic acid. BMC Genomics 16:288. doi: $10.1186 /$ s12864-015-1440-5

Djami-Tchatchou, A. T., and Straker, C. J. (2012). The isolation of high quality RNA from the fruit of avocado (Persea americana Mill.). South African J. Bot. 78, 44-46. doi: 10.1016/j.sajb.2011.04.009

Foundation for Statistical Computing (2013). The $R$ Project for Statistical Computing.

Freeman, S., Katan, T., and Shabi, E. (1996). Characterization of Colletotrichum gloeosporioides isolates from avocado and almond fruits with molecular and pathogenicity tests. Appl. Environ. Microbiol. 62, 1014-1020.

Hadwiger, L. (2008). Pea-Fusarium solani interactions contributions of a system toward understanding disease resistance. Phytopathology 98, 372-379. doi: 10.1094/PHYTO-98-4-0372

Hadwiger, L. A. (2013). Plant science review: multiple effects of chitosan on plant systems: solid science or hype. Plant Sci. 208, 42-49. doi: 10.1016/j.plantsci.2013.03.007

Hartney, S., Carson, J., and Hadwiger, L. A. (2007). The use of chemical genomics to detect functional systems affecting the non-host disease resistance of pea to Fusarium solani f. sp. phaseoli. Plant Sci. 172, 45-56. doi: 10.1016/j.plantsci.2006.07.014

Ibarra-Laclette, E., Méndez-Bravo, A., Pérez-Torres, C. A., Albert, V. A., Mockaitis, K., Kilaru, A., et al. (2015). Deep sequencing of the Mexican avocado transcriptome, an ancient angiosperm with a high content of fatty acids. BMC Genomics 16:599. doi: 10.1186/s12864-015-1775-y

Iriti, M., and Faoro, F. (2009). Chitosan as a MAMP, searching for a PRR. J. Exp. Bot. 4, 66-68. doi: 10.4161/psb.4.1.7408

Islam, M., Masum, S., Rahman, M. M., Islam, A., and Shaikh, A. A. (2011). Preparation of chitosan from shrimp shell and investigation of its properties. Int. J. Basic Appl. Sci. 11, 77-80. Available online at: http://www.ijens.org/Vol \%2011\%20I\%2001/110201-8484\%20IJBAS-IJENS.pdf
Joung, J.-G., Corbett, A. M., Fellman, S. M., Tieman, D. M., Klee, H. J., Giovannoni, J. J., et al. (2009). Plant MetGenMAP: an integrative analysis system for plant systems biology. Plant Physiol. 151, 1758-1768. doi: 10.1104/pp.109. 145169

Jung, H. W., Tschaplinski, T. J., Wang, L., Glazebrook, J., and Greenberg, J. T. (2009). Priming in systemic plant immunity. Science 324, 89-91. doi: $10.1126 /$ science.1170025

Khan, W., Prithiviraj, B., and Smith, D. L. (2003). Chitosan and chitin oligomers increase phenylalanine ammonia-lyase and tyrosine ammonia-lyase activities in soybean leaves. J. Plant Physiol. 160, 859-863. doi: 10.1078/0176-1617-00905

Kilaru, A., Cao, X., Dabbs, P. B., Sung, H.-J., Rahman, M. M., Thrower, N., et al. (2015). Oil biosynthesis in a basal angiosperm: transcriptome analysis of Persea Americana mesocarp. BMC Plant Biol. 15:203. doi: 10.1186/s12870-015-0586-2

Kohle, H., Jeblick, W., Poten, F., Blaschek, W., and Kauss, H. (1985). Chitosanelicited callose synthesis in soybean cells as a ca-dependent process. Plant Physiol. 77, 544-551. doi: 10.1104/pp.77.3.544

Langmead, B., and Salzberg, S. L. (2012). Fast gapped-read alignment with Bowtie 2. Nat. Methods 9, 357-359. doi: 10.1038/nmeth.1923

Lin, W., Hu, X., Zhang, W., John Rogers, W., and Cai, W. (2005). Hydrogen peroxide mediates defence responses induced by chitosans of different molecular weights in rice. J. Plant Physiol. 162, 937-944. doi: 10.1016/j.jplph.2004.10.003

Liu, J., Tian, S., Meng, X., and Xu, Y. (2007). Effects of chitosan on control of postharvest diseases and physiological responses of tomato fruit. Postharvest Biol. Technol. 44, 300-306. doi: 10.1016/j.postharvbio.2006.12.019

McCarthy, D. J., Chen, Y., and Smyth, G. K. (2012). Differential expression analysis of multifactor RNA-Seq experiments with respect to biological variation. Nucleic Acids Res. 40, 4288-4297. doi: 10.1093/nar/gks042

Mendgen, K., and Hahn, M. (2002). Plant infection and the establishment of fungal biotrophy. Trends Plant Sci. 7, 352-356. doi: 10.1016/S1360-1385(02)02297-5

Mendy, B., Wanjiku, M., Radakovic, Z. S., Holbein, J., Ilyas, M., Chopra, D., et al. (2017). Arabidopsis leucine-rich repeat receptor - like kinase NILR1 is required for induction of innate immunity to parasitic nematodes. PLoS Pathog. 13:e1006284. doi: 10.1371/journal.ppat.1006284

Meng, X., Yang, L., Kennedy, J. F., and Tian, S. (2010). Effects of chitosan and oligochitosan on growth of two fungal pathogens and physiological properties in pear fruit. Carbohydr. Polym. 81, 70-75. doi: 10.1016/j.carbpol.2010.01.057

Meteignier, L.-V., El Oirdi, M., Cohen, M., Barff, T., Matteau, D., Lucier, J.-F., et al. (2017). Translatome analysis of an NB-LRR immune response identifies important contributors to plant immunity in Arabidopsis. J. Exp. Bot. 211, 1020-1034. doi: 10.1093/jxb/erx078

Oñate-Sánchez, L., and Singh, K. B. (2002). Identification of Arabidopsis ethyleneresponsive element binding factors with distinct induction kinetics after pathogen infection. Plant Physiol. 128, 1313-1322. doi: 10.1104/pp.010862

Paulert, R., Ebbinghaus, D., Urlass, C., and Moerschbacher, B. M. (2010). Priming of the oxidative burst in rice and wheat cell cultures by ulvan, a polysaccharide from green macroalgae, and enhanced resistance against powdery mildew in wheat and barley plants. Plant Pathol. 59, 634-642. doi: 10.1111/j.1365-3059.2010.02300.x

Pieterse, C. M. J., Zamioudis, C., Berendsen, R. L., Weller, D. M., Van Wees, S. C. M., and Bakker, P. A. H. M. (2014). Induced systemic resistance by beneficial microbes. Annu. Rev. Phytopathol. 52, 347-375. doi: 10.1146/annurev-phyto-082712-102340

Povero, G., Loreti, E., Pucciariello, C., Santaniello, A., Di Tommaso, D., Di Tommaso, G., et al. (2011). Transcript profiling of chitosan-treated Arabidopsis seedlings. J. Plant Res. 124, 619-629. doi: 10.1007/s10265-010-0399-1

Provart, N., and Tong, Z. (2003). A browser-based functional Classification SuperViewer for Arabidopsis genomics. Can. J. Bot. 2003, 271-272. Available online at: http://labs.csb.utoronto.ca/provart/Provart\%20and \%20Zhu\%20(2003)\%20Curr\%20Comp\%20Mol\%20Biol_2003;271-2_A \%20Browser-based\%20Functional\%20Classification\%20SuperViewer\%20for \%20Arabidopsis\%20Genomics.pdf

Prusky, D., and Lichter, A. (2007). Activation of quiescent infections by postharvest pathogens during transition from the biotrophic to the necrotrophic stage. FEMS Microbiol. Lett. 268, 1-8. doi: 10.1111/j.1574-6968.2006.00603.x

Roberts, A., and Pachter, L. (2013). Streaming fragment assignment for real-time analysis of sequencing experiments. Nat. Methods 10, 71-73. doi: $10.1038 /$ nmeth. 2251 
Rodríguez-Carpena, J.-G., Morcuende, D., Andrade, M.-J., Kylli, P., and Estévez, M. (2011). Avocado (Persea americana Mill.) phenolics, in vitro antioxidant and antimicrobial activities, and inhibition of lipid and protein oxidation in porcine patties. J. Agric. Food Chem. 59, 5625-5635. doi: 10.1021/ jf1048832

Rodríguez-López, E. S., Manuel, J., Netzahualcoyotl, G., Nacional, I. P., Genómica, C. D. B., Mendoza, C. N., et al. (2009). La Infección de Colletotrichum gloeosporioides (Penz.) Penz. y Sacc. en Aguacatero (Persea americana Mill.): Aspectos Bioquímicos y Genéticos. Rev. Mex. Fitopatol. 27, 53-63. Available online at: http://www.scielo.org.mx/scielo.php?script=sci_arttext\&pid=S018533092009000100007\&lng=es\&nrm =iso

Terry, L. A., and Joyce, D. C. (2004). Elicitors of induced disease resistance in postharvest horticultural crops: a brief review. Postharvest Biol. Technol. 32, 1-13. doi: 10.1016/j.postharvbio.2003.09.016

Usadel, B., Poree, F., Nagel, A., Lohse, M., Czedik-Eysenberg, A., and Stitt, M. (2009). A guide to using MapMan to visualize and compare Omics data in plants: a case study in the crop species, Maize. Plant Cell Environ. 32, 1211-1229. doi: 10.1111/j.1365-3040.2009.01978.x

Vallejo-Reyna, M. A., Santamaría, J. M., Rodríguez-Zapata, L. C., HerreraValencia, V. A., and Peraza-Echeverria, S. (2015). Identification of novel ERF transcription factor genes in papaya and analysis of their expression in different tissues and in response to the plant defense inducer benzothiadiazole (BTH). Physiol. Mol. Plant Pathol. 91, 141-151. doi: 10.1016/j.pmpp.2015.06.005

Wang, W., Bostic, T. R., and Gu, L. (2010). Antioxidant capacities, procyanidins and pigments in avocados of different strains and cultivars. Food Chem. 122, 1193-1198. doi: 10.1016/j.foodchem.2010.03.114

Wang, Y., Cordewener, J. H. G., America, A. H. P., Shan, W., Bouwmeester, K., and Govers, F. (2015). Arabidopsis lectin receptor kinases LecRK-IX.1 and LecRKIX.2 Are functional analogs in regulating phytophthora resistance and plant cell death. MPMI 28, 1032-1048. doi: 10.1094/MPMI-02-15-0025-R

Wharton, P. S., and Diéguez-Uribeondo, J. (2004). The biology of Colletotrichum acutatum An. del Jard. bontánico madrid 61, 3-22. doi: 10.3989/ajbm.2004.v61.i1.61

White T. J., Bruns T., Lee S., and Taylor J. (1990). "Amplification and direct sequencing of fungal ribosomal RNA genes for phylognetics," in Genetics and Evolution (Academic Press), 315-322.

Widsten, P., Cruz, C. D., Fletcher, G. C., Pajak, M. A., and McGhie, T. K. (2014). Tannins and extracts of fruit byproducts: antibacterial activity against foodborne bacteria and antioxidant capacity. J. Agric. Food Chem. 62, 11146-11156. doi: 10.1021/jf503819t

Yakoby, N., Beno-Moualem, D., Kobiler, I., and Prusky, D. (2002). The analysis of fruit protection mechanisms provided by reducedpathogenicity mutants of colletotrichum gloeosporioides obtained by restriction enzyme mediated integration. Phytopathology 92, 1196-1201. doi: 10.1094/PHYTO.2002.92.11.1196

Yin, H., Zhao, X., Bai, X., and Du, Y. (2009). Molecular cloning and characterization of a Brassica napus L. MAP kinase involved in oligochitosan-induced defense signaling. Plant Mol. Biol. Report 28, 292-301. doi: 10.1007/s11105-009-0152-X

Zuppini, A., Baldan, B., Millioni, R., Favaron, F., Navazio, L., and Mariani, P. (2004). Chitosan induces Ca2+-mediated programmed cell death in soybean cells. New Phytol. 161, 557-568. doi: 10.1046/j.1469-8137.2003.00969.x

Conflict of Interest Statement: The authors declare that the research was conducted in the absence of any commercial or financial relationships that could be construed as a potential conflict of interest.

The reviewer OVL declared a shared affiliation, though no other collaboration, with one of the authors JVA to the handling Editor, who ensured that the process met the standards of a fair and objective review.

Copyright (c) 2017 Xoca-Orozco, Cuellar-Torres, González-Morales, GutiérrezMartínez, López-García, Herrera-Estrella, Vega-Arreguín and Chacón-López. This is an open-access article distributed under the terms of the Creative Commons Attribution License (CC BY). The use, distribution or reproduction in other forums is permitted, provided the original author(s) or licensor are credited and that the original publication in this journal is cited, in accordance with accepted academic practice. No use, distribution or reproduction is permitted which does not comply with these terms. 